\title{
ANÁLISE DA TEMPERATURA INTERNA E SUPERFICIAL EM DIFERENTES SOMBREAMENTOS ARBÓREOS
}

\author{
ANALYSIS OF INTERNAL AND SURFACE TEMPERATURES IN DIFFERENT \\ WOODED SHADES
}

\begin{abstract}
Karyn Ferreira Antunes Ribeiro ${ }^{1}$, Marcos de Oliveira Valin $\mathrm{Jr}^{2}$, Flávia Maria de Moura Santos ${ }^{3}$, Marta Cristina de Jesus Albuquerque Nogueira ${ }^{4}$, José de Souza Nogueira ${ }^{5}$, Carlo Raph De Musis ${ }^{6}$
\end{abstract}

\begin{abstract}
RESUMO
O objetivo deste estudo foi analisar a diferença de temperatura de materiais utilizados em superfícies urbanas, expostos ao sombreamento de duas espécies Mangifera indica L. (mangueira) e Licania tomentosa B. (oiti), tendo como referencial esses mesmos materiais sem nenhum sombreamento, e determinar qual espécie é a mais adequada para arborização da capital Mato-grossense. Foram realizadas medidas de temperaturas internas e superficiais nos seguintes materiais: solo natural, concreto e asfalto. Os resultados indicaram que a espécie arbórea que obteve melhor desempenho térmico nos diferentes materiais foi Mangifera indica. $O$ material que apresentou menores temperaturas nos diferentes sombreamentos foi o solo. A maior variação térmica interna apresentada foi no material asfalto entre os ambientes Mangifera indica e sem sombreamento, às 12:00 horas, com $16,4{ }^{\circ} \mathrm{C}$. Portanto, cabe ressaltar a importância da arborização e da utilização de materiais permeáveis nas cidades para proporcionar melhor conforto térmico aos usuários.
\end{abstract}

Palavras-chave: Arborização urbana; Mangifera indica; Licania tomentosa; Superfícies urbanas

\begin{abstract}
The objective of this study was to analyze the difference in temperature of materials used in urban surface areas, exposed to the shading of two species Mangifera indica L. (mango tree) and Licania tomentosa B. (oiti), taking as reference those same materials without any shading and determine which species is most suitable for afforestation of Mato Grosso capital. Internal and surface temperatures were measured in the following materials: natural soil, concrete and asphalt. The results indicated that the tree species that got better thermal performance in different materials was Mangifera indica. The material that presented lower temperatures in different shades was the soil. Most internal thermal variation was presented in the material asphalt between Mangifera indica environments and without shading, at $12: 00 \mathrm{pm}$, with $16.4^{\circ} \mathrm{C}$. Therefore, it is worth noting the importance of afforestation and the use of permeable materials in the cities to provide better thermal comfort to users.
\end{abstract}

Keywords: Urban Afforestation; Mangifera indica; Licania tomentosa; Urban surfaces

\footnotetext{
Recebido em 14.09.2015 e aceito em 21.10.2015

1 Mestranda em Física Ambiental, Universidade Federal de Mato Grosso, UFMT - Cuiabá-MT - karyn.ribeiro@cba.ifmt.edu.br

2 Mestrando em Física Ambiental, Universidade Federal de Mato Grosso, UFMT - Cuiabá-MT - marcos.valin@cba.ifmt.edu.br

3 Dra. Professora do Programa de Pós-Graduação em Física Ambiental, UFMT - Cuiabá-MT - flavia_mms@hotmail.com

4 Dra. Professora do Programa de Pós-Graduação em Física Ambiental, UFMT - Cuiabá-MT - mcjanp@gmail.com

5 Dr. Coordenador do Programa de Pós-Graduação em Física Ambiental, UFMT - Cuiabá-MT - nogueira@ufmt.br

6 Dr. Professor do Programa de Pós-Graduação em Física Ambiental, UFMT - Cuiabá-MT - carlo.demusis@gmail.com
} 


\section{INTRODUÇÃO}

Grande parte dos países em desenvolvimento tiveram seus crescimentos populacionais e urbanísticos de forma rápida e sem planejamento. Segundo Callejas et al. (2011), o intenso crescimento e a concentração populacional nos seus centros urbanos têm favorecido o processo de mudanças microclimáticas locais, em função das alterações das superfícies do solo e da ausência da arborização.

Para Maciel, Nogueira e Nogueira (2011), nas últimas décadas o crescimento e a concentração das populações nos centros urbanos têm acelerado o processo de mudança da cobertura das superfícies do solo, contribuído para o fenômeno das ilhas de calor.

Segundo Alves e Vecchia (2012), o ambiente urbano absorve e emite uma quantidade maior de energia em relação a áreas rurais, pelo fato de que os materiais típicos de uma superfície urbana apresentam, em média, menor albedo, menor capacidade térmica e maior condutividade de calor. Isso ocorre devido suas propriedades e características termo-físicas, que resultam no incremento na temperatura do ar.

Em Cuiabá essa situação não é diferente, sendo na verdade, mais agravante, pois possui elevadas temperaturas e pouca nebulosidade praticamente o ano inteiro, sendo considerada uma das capitais mais quente do Brasil. Devido à ausência de vegetação, ocorre a incidência direta da radiação solar, provocando desconforto térmico aos usuários.

As copas das árvores têm um papel importante na atenuação da radiação e consequentemente redução da amplitude térmica em áreas adjacentes. Segundo Oliveira (2011), uma das soluções para amenizar os problemas causados pela urbanização é tratar o meio urbano com vegetação, por meio da arborização de vias públicas e da criação de áreas naturais protegidas.

Para Nince et al. (2014), os efeitos diretos do sombreamento pela vegetação podem ser quantificados por meio das medições da temperatura de superfície de materiais expostos e protegidos pelas copas das árvores. Uma área sombreada é fracamente atingida pela radiação solar direta incidente e, assim, a temperatura radiante daquela superfície é menor, o que diminui a radiação de ondas longas emitida.

A arborização urbana desempenha funções muito importantes nas cidades, desde sombreamento para pedestre e carro até o melhoramento da qualidade do ar. Segundo Almeida Júnior (2005), as espécies arbóreas mais utilizadas pela Prefeitura de Cuiabá/MT para arborização urbana são: Lophantera lactescens (chuva de ouro), Delonix regia (flamboyant), Ficus benjamina (fícus), Mangifera indica, Licania tomentosa, Caesalpinia peltophoroides (sibipiruna), Terminalia catappa (sete copas) e Vitex montevidensis (tarumã). 
As espécies arbóreas Licania tomentosa e Mangifera indica, foram selecionadas para este estudo, pois são apropriadas para o clima de Cuiabá, que se adaptam às condições locais e proporcionam alterações microclimáticas positivas em função do sombreamento promovido (ALMEIDA JÚNIOR, 2005).

As principais características de Licania tomentosa são: árvore com fuste bem definido, copa arredondada e fechada, com folhagem densa, conferindo-lhe excelente sombra. Portanto sendo uma espécie recomendada para arborização de praças e parques (OLIVEIRA, 2011).

As principais características de Mangifera indica são: árvore de grande porte (até $30 \mathrm{~m}$ ), frondosa, perenifólia, com copa densa e folhas verdes lineares. Originária do sul da Ásia, a manga dispersou-se por todos os continentes, sendo cultivada, atualmente, em todos os países de clima tropical e subtropical (OLIVEIRA, 2008). Segundo Lima Neto e Melo e Souza (2011) a árvore da espécie Mangifera indica é importante atrativo para fauna por causa do seu fruto. O grande problema que geralmente apresenta é o sistema radicular que não responde bem ao solo urbano compactado, levantando por vezes as construções.

Para Durante e Nogueira (2013), se as copas das árvores forem densas, podem servir como barreira para o ruído, captando a poeira em suas folhas e filtrando $o$ ar, proporcionando privacidade e controlando o iluminamento excessivo do sol. Nos climas quentes, as superfícies vegetadas e as folhas das árvores absorvem a radiação solar, o sombreamento reduz as temperaturas superficiais e, o processo de evapotranspiração irá diminuir a temperatura do ar.

Segundo os mesmos autores, outro fator que está interligado com as copas das árvores é o Índice de Área Foliar (IAF), definido pela relação entre a superfície foliar e a superfície de projeção da copa no solo $\left(\mathrm{m}^{2} / \mathrm{m}^{2}\right)$, possui seu montante diretamente proporcional a densidade da copa. O IAF é utilizado para avaliar o desenvolvimento das plantas, que irá influenciar no fluxo de calor no solo e nas temperaturas superficiais das áreas sombreadas. Assim sendo, os benefícios da arborização urbana se estendem para qualquer local.

O objetivo deste trabalho foi analisar a influência do sombreamento arbóreo no comportamento térmico de diferentes materiais construtivos e determinar qual espécie é mais adequada para arborização da capital Mato-grossense. 


\section{MATERIAL E MÉTODOS}

Esta pesquisa foi desenvolvida na cidade de Cuiabá (Figura 1), no campus da Universidade Federal de Mato Grosso (UFMT), localizado na Av. Fernando Correa da Costa, que apresenta uma área de 74 hectares, sendo caracterizado por um ambiente heterogêneo, com diferentes superfícies urbanas de uso e ocupação do solo.

Segundo Alves e Biudes (2012), o clima de Cuiabá é do tipo Aw, segundo a classificação de Köppen, identificado prioritariamente pela temperatura, apresentando duas estações bem definidas: uma seca, de abril a outubro, e outra chuvosa, de novembro a março, com médias entre 28 e $32^{\circ} \mathrm{C}$.

Santos et al. (2014) complementam que o clima de Cuiabá é tropical continental, sem influência marítima, onde já foi detectada a interferência do uso do solo urbano na ocorrência de ilhas de calor.

Segundo Nince et al. (2014), a cobertura vegetal de Cuiabá é constituída por remanescentes de cerrado, cerradão, matas ciliares no entorno dos rios e por vegetação exótica.

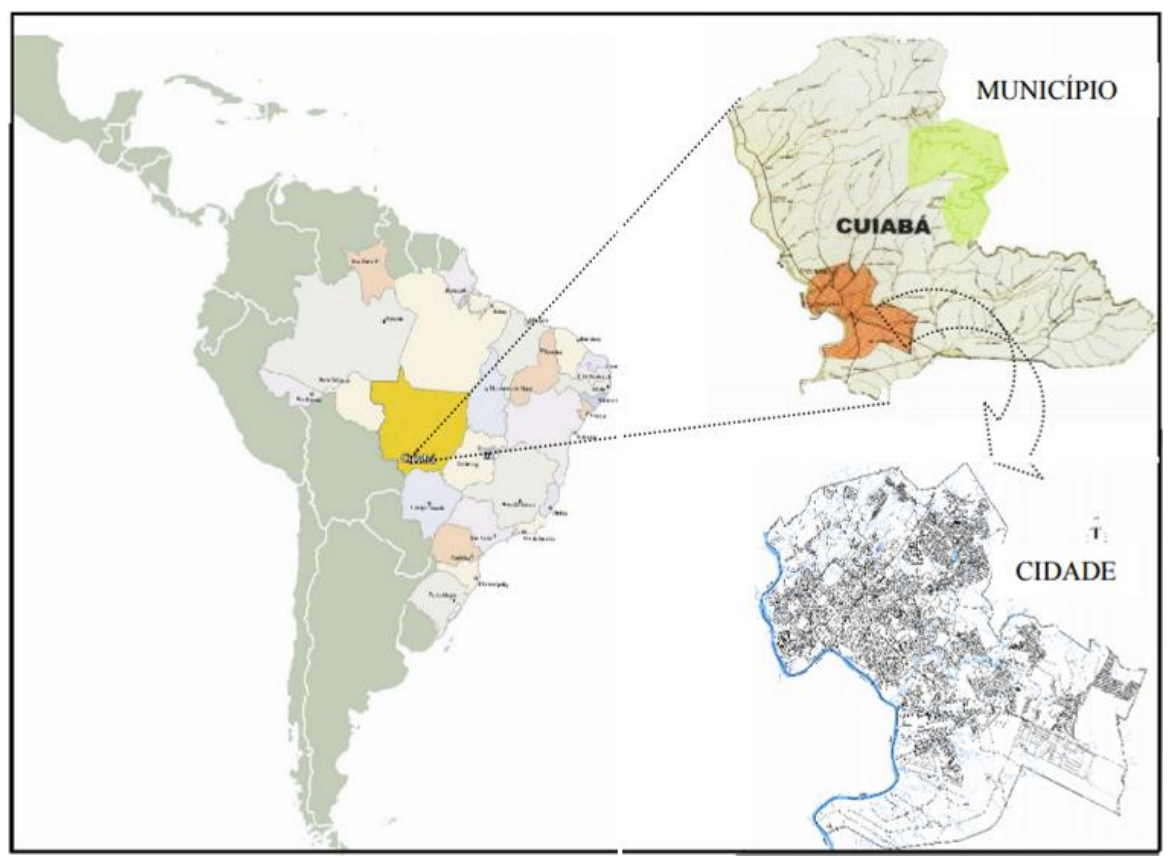

Fonte: Instituto de Pesquisa e Desenvolvimento Urbano (IPDU) de Cuiabá (2006).

Figura 1. Localização da área de estudo, em destaque o município de Cuiabá - MT Figure 1. Location of the study area, highlighted the city of Cuiaba - MT

A Figura 2 mostra a localização dos pontos onde foram coletados os dados das temperaturas internas e superficiais de diferentes tipos de superfícies urbanas, sob a influência do sombreamento arbóreo de duas espécies: Mangifera indica e Licania 
tomentosa. As árvores em estudo estão localizadas em frente ao bloco da Pós-Graduação em Física Ambiental (PGFA).

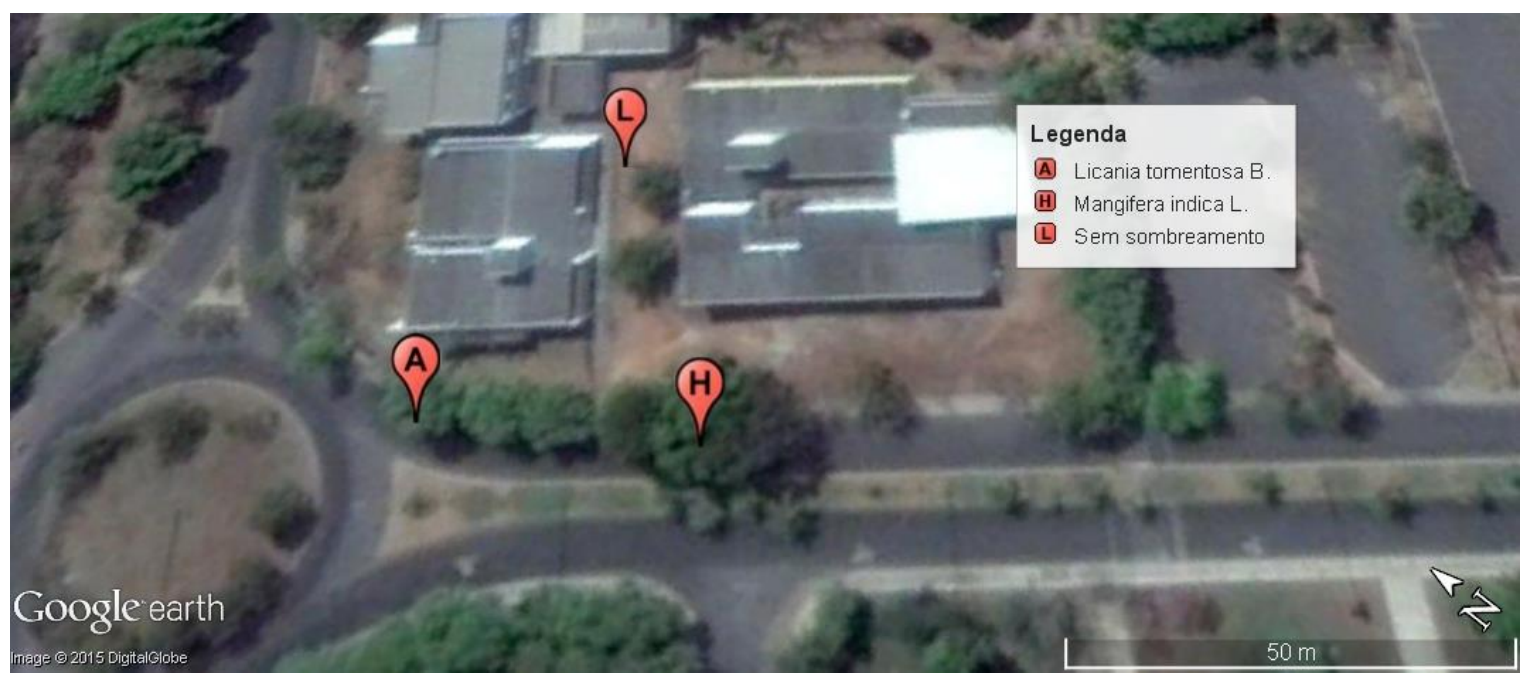

Fonte: Google earth (adaptado), 2015.

Figura 2. Localização dos pontos de coleta de dados no campus da UFMT - A (Mangifera indica) - H (Licania tomentosa) e L (sem sombreamento)

Figure 2. Location of data collection points on the campus of UFMT - A (Mangifera indica) - H (Licania tomentosa) and $\mathrm{L}$ (no shading)

Na Figura 3 a letra "L" identifica as superfícies urbanas sem a influência do sombreamento arbóreo. As espécies arbóreas legendadas por "K" e "J" estão afastadas, não sendo consideradas nos modelos. A espécie arbórea Licania tomentosa foi identificada pela letra "A" e a Mangifera indica pela letra "H".

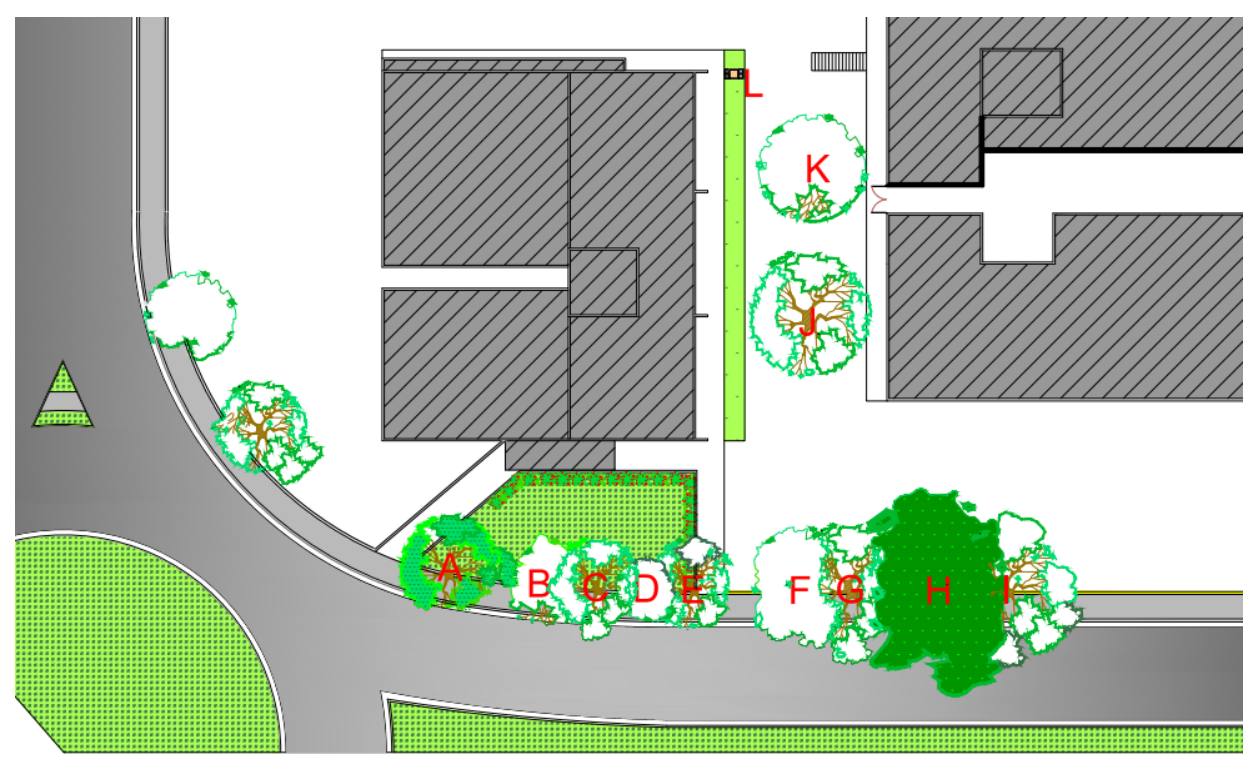

Figura 3. Planta baixa do local em estudo, destacando os pontos de coleta por letra alfabética Figure 3. Floor plan of the study area, highlighting the points of collection in alphabetical letter 
$\mathrm{Na}$ Figura 4, são descritos como foram realizadas as coletas e os significados de suas abreviaturas.
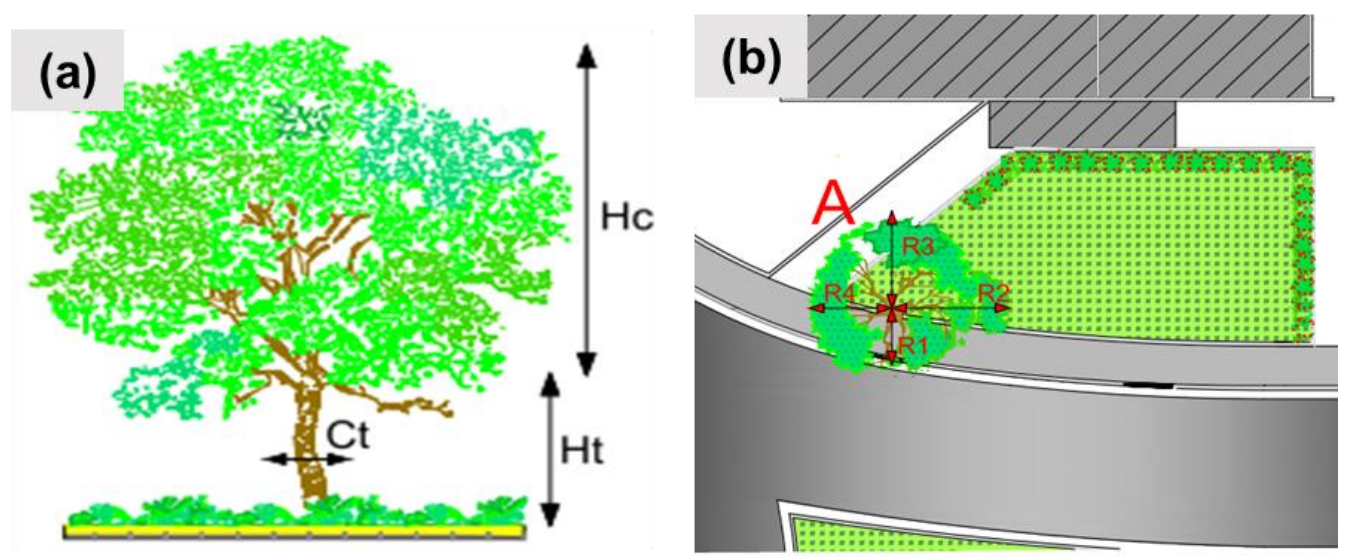

Figura 4. Identificação das abreviaturas utilizadas na característica das espécies. (a) Altura do tronco $(\mathrm{Ht})$, da copa (Hc) e circunferência do tronco (Ct). (b) Raios das copas (R1, R2, R3 e R4)

Figure 4. Identification of abbreviations used in the characteristic of the species. (a) Trunk height $(\mathrm{Ht})$, canopy $(\mathrm{Hc})$ and trunk circumference (Ct). (b) canopy rays (R1, R2, R3 e R4)

As características das espécies arbóreas estudas estão apresentadas na Tabela 1.

Tabela 1. Características das espécies arbóreas

Table 1. Characteristics of tree species

\begin{tabular}{|c|c|c|c|c|c|c|c|c|}
\hline \multirow{2}{*}{ Árvore } & \multicolumn{3}{|c|}{ Altura (m) } & \multirow{2}{*}{$\begin{array}{l}\text { Circunf. } \\
\text { Tronco } \\
(\mathrm{Ct}-\mathrm{m})\end{array}$} & \multicolumn{4}{|c|}{ Raio (m) } \\
\hline & $\begin{array}{c}\text { Tronco } \\
(\mathrm{Ht})\end{array}$ & $\begin{array}{l}\text { Copa } \\
\text { (Hc }\end{array}$ & $\begin{array}{l}\text { Total } \\
(\mathrm{Hc})\end{array}$ & & $\mathrm{R} 1$ & $\mathrm{R} 2$ & R3 & R4 \\
\hline A & 3,3 & 6,3 & 9,6 & 1,52 & 2,65 & 4,90 & 4,10 & 3,60 \\
\hline $\mathrm{B}$ & 2,5 & 4,9 & 7,4 & 0,94 & 3,05 & 2,10 & 3,70 & 1,95 \\
\hline C & 3,3 & 5,3 & 8,6 & 1,50 & 3,90 & 2,90 & 3,67 & 3,60 \\
\hline $\mathrm{D}$ & 2,5 & 4,9 & 7,4 & 0,46 & \multicolumn{4}{|c|}{ Raio da copa muito pequena para medir } \\
\hline$E$ & 3,6 & 5,0 & 8,6 & 1,15 & 3,00 & 2,48 & 3,90 & 3,70 \\
\hline $\mathrm{F}$ & 3,0 & 6,1 & 9,1 & 1,30 & 4,40 & 2,25 & 4,50 & 3,18 \\
\hline$G$ & 4,0 & 9,4 & 13,4 & 1,08 & 5,14 & 2,30 & 4,50 & 4,30 \\
\hline $\mathrm{H}$ & 3,6 & 8,9 & 12,5 & 1,72 & 7,60 & 5,10 & 7,39 & 4,50 \\
\hline $\mathrm{I}$ & 4,3 & 9,7 & 14,0 & 1,45 & 5,75 & 5,45 & 5,80 & 4,34 \\
\hline
\end{tabular}

Na Tabela 2 estão apresentadas as distâncias dos eixos, em metros, das espécies arbóreas entre si, pois como estão próximas podem influenciar as características microclimáticas dos pontos $\mathrm{A}$ e $\mathrm{H}$. 
Tabela 2. Distância em metros entre os eixos dos trocos das espécies arbóreas Table 2. Distance in meters between the axes of the trunks of tree species

\begin{tabular}{c|c}
\hline $\begin{array}{c}\text { Espécies } \\
\text { Arbóreas }\end{array}$ & $\begin{array}{c}\text { Distância } \\
(\mathrm{m})\end{array}$ \\
\hline $\mathrm{A}-\mathrm{B}$ & 6,56 \\
\hline $\mathrm{B}-\mathrm{C}$ & 4,20 \\
\hline $\mathrm{C}-\mathrm{D}$ & 3,70 \\
\hline $\mathrm{D}-\mathrm{E}$ & 3,30 \\
\hline $\mathrm{E}-\mathrm{F}$ & 7,80 \\
\hline $\mathrm{F}-\mathrm{G}$ & 3,70 \\
\hline $\mathrm{G}-\mathrm{H}$ & 6,50 \\
\hline $\mathrm{H}-\mathrm{I}$ & 4,90 \\
\hline
\end{tabular}

Para a realização desta pesquisa, foram confeccionadas placas de tamanhos variados de materiais construtivos de solo, concreto e asfalto. As placas foram confeccionadas das seguintes formas:

I. Placa de solo - o solo utilizado nas placas foi da região da Baixada Cuiabana, denominado solo saprolítico de filito (RIBEIRO, 2006). O solo estava com $21 \%$ de umidade ao ser compactado por um soquete cilíndrico de concreto $(15 \times 30 \mathrm{~cm})$ em forma de madeira. As dimensões das placas de solos foram $60 \times 60 \times 10 \mathrm{~cm}$, possuindo três unidades, conforme Figura 5.
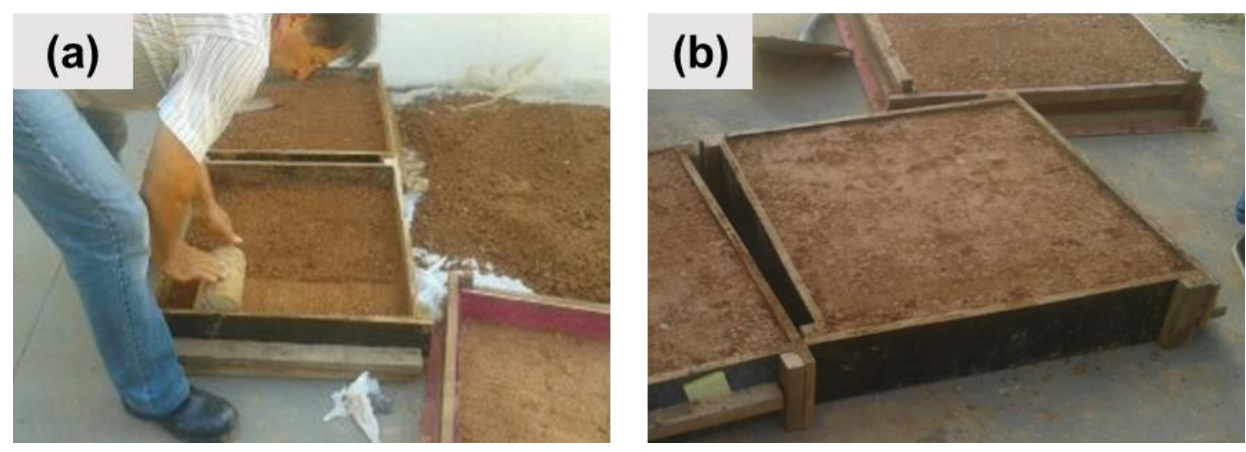

Figura 5. Placas de solo - (a) compactando o solo na placa - (b) placas prontas Figure 5. Soil plates - (a) compacting the soil on the board - (b) finished plates

II. Placa de concreto - o concreto foi dosado na betoneira com o traço (1:2,12:2,88:0,5 cimento:areia:brita:água), lançado e adensado com uma haste metálica em forma de madeira com dimensões $(20 \times 20 \mathrm{~cm})$. A cura foi realizada por 7 dias, através de molhamento com água, sendo, na sequência, cobertas por lona. As dimensões das placas de concreto foram $30 \times 30 \times 10 \mathrm{~cm}$. Foram confeccionadas oito unidades, pois seria difícil manusear uma placa com maiores dimensões devido à massa das mesmas, conforme a Figura 6. 

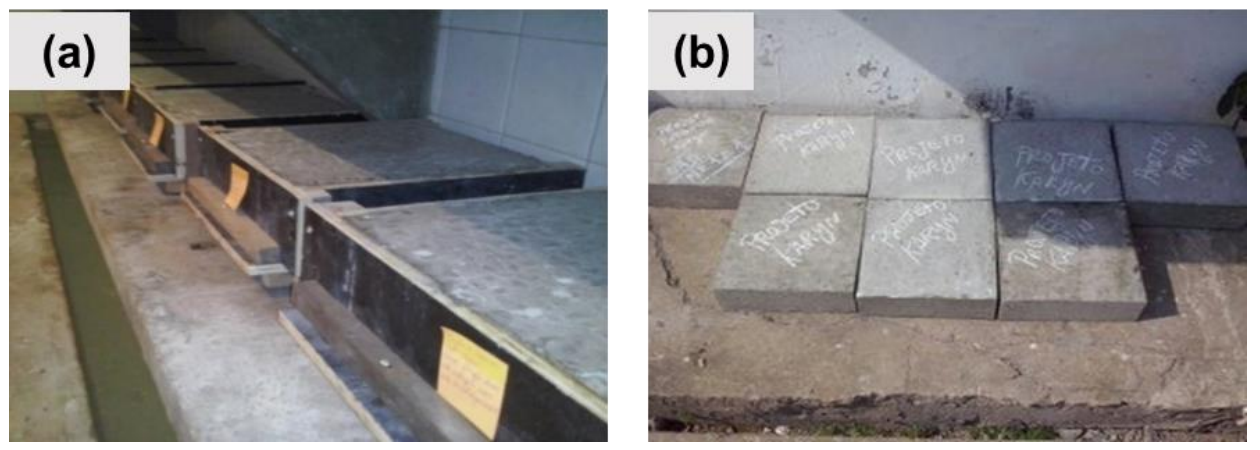

Figura 6. Placas de concreto - (a) com as fôrmas de madeira - (b) as placas prontas

Figure 6. Concrete blocks - (a) with the wooden formwork - (b) the finished plates

III. Placa de asfalto - a placa de asfalto foi confeccionada com traço (1:4,81:10,3:2,06:0,3 emulsão:areia:pedrisco:brita:água) de Pré-Misturado à Frio (PMF), muito utilizado em "tapa buracos" nas cidades. O ligante usado foi a emulsão asfáltica (RL $1 C$ ) e os agregados foram: areia, pedrisco e brita 1. O material foi homogeneizado, lançando e compactado com soquete padrão de asfalto na forma de madeira. Segundo a Brasquímica (2015), a emulsão asfáltica RL 1C "é um sistema constituído de uma fase asfáltica (glóbulos com diâmetro médio de 3 micras) dispersa em uma fase aquosa química tenso-ativa e foi desenvolvido para aplicação à temperatura ambiente em serviços de pavimentação asfáltica". A cura da mistura asfáltica ocorreu pela evaporação da umidade contida na mesma. As dimensões das placas de asfalto foram de $30 \times 30 \times 10 \mathrm{~cm}$, sendo inviável confeccionar em maiores dimensões por causa da massa das mesmas. O total de placas confeccionadas foram oito, conforme Figura 7.

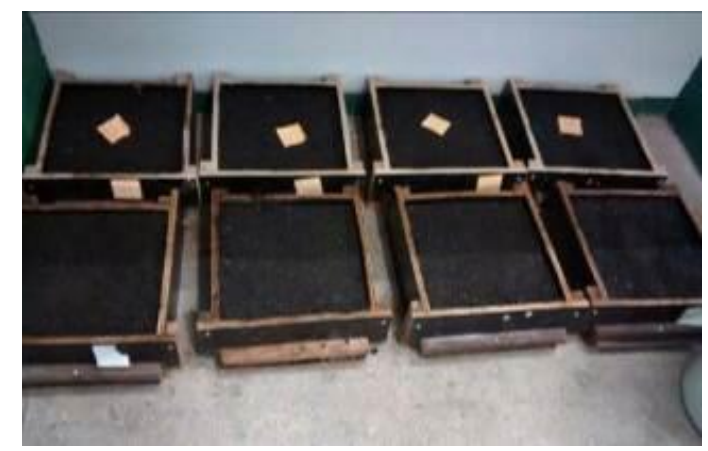

Figura 7. Placas de asfalto (PMF) finalizadas nas placas de madeira

Figure 7. Asphalt plates (PMF) finished in wooden boards

\section{Descrições dos equipamentos utilizados}

Os dataloggers utilizados foram do modelo HOBO U12-012, com sensor externo TMC20-HB, devidamente aferidos para a realização dessa pesquisa. O sensor TMC20-HD é 
capaz de medir a temperatura do ar, água ou solo com cabo de 6,1 metros, sendo utilizado para uso em ambientes internos, externos ou subaquáticos.

Foram utilizados portes de sorvete como abrigo dos dataloggers (Figura 8 b), para garantir a circulação de ar foram realizados furos nas caixas. Os cabos com sensores externos foram instalados no centro das placas, há $5 \mathrm{~cm}$ de profundidade das superfícies.
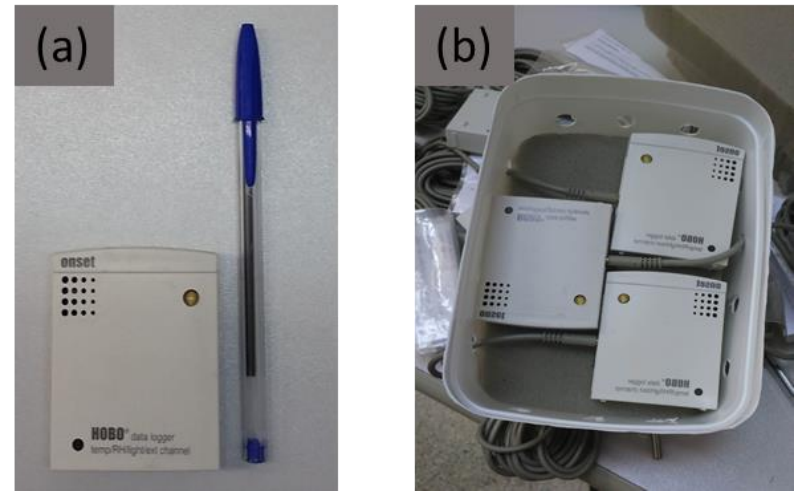

Figura 8. Datalogger - (a) modelo e dimensões comparadas de uma caneta - (b) equipamento dentro do abrigo de pote de sorvete

Figure 8. Datalogger - (a) model and dimensions compared to a pen - (b) equipment within the ice cream pot shelter

Os abrigos foram instalados sob a copa de duas espécies arbóreas (Licania tomentosa e Mangifera indica) e uma atrás do "quebra-sol" (Figura 9). As coletas dos dados foram realizadas de 18/03/2014 a 04/05/2015 no período quente-úmido. Os dados foram registrados a cada 10 minutos e as médias dos dados foram realizadas a cada hora.
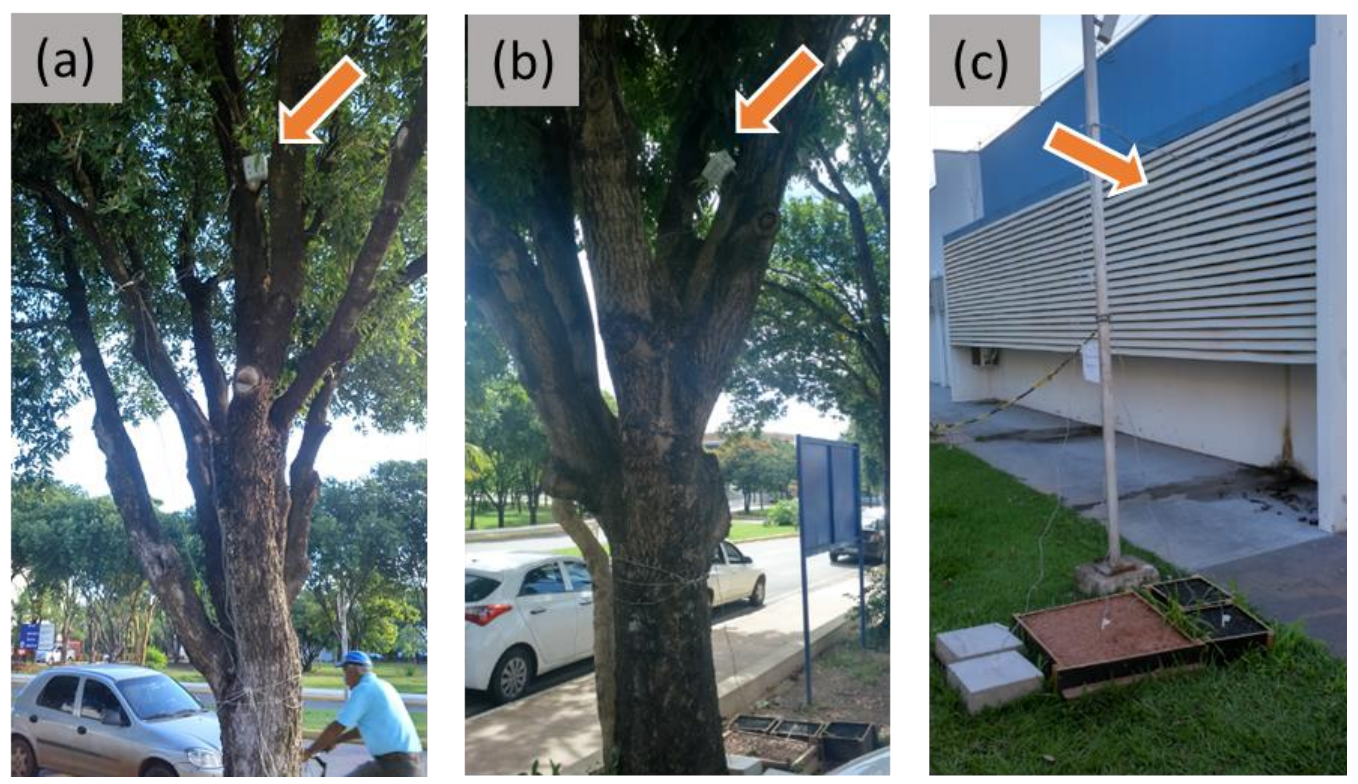

Figura 9. Abrigos instalados - (a) espécie Licania tomentosa - (b) espécie Mangifera indica - (c) atrás do "quebra-sol"

Figure 9. Installed Shelters - (a) species Licania tomentosa - (b) species Mangifera indica - (c) behind the "sun visor" 
Para medição da temperatura superficial foi utilizado o termômetro digital infravermelho com mira laser (Minipa modelo MT-360), conforme a Figura 10. O equipamento opera em intervalo de temperatura do ar de $-30^{\circ} \mathrm{C}$ a $550^{\circ} \mathrm{C}$, com resolução de $\left(0,5^{\circ} \mathrm{C} / 1^{\circ} \mathrm{C}\right)$.

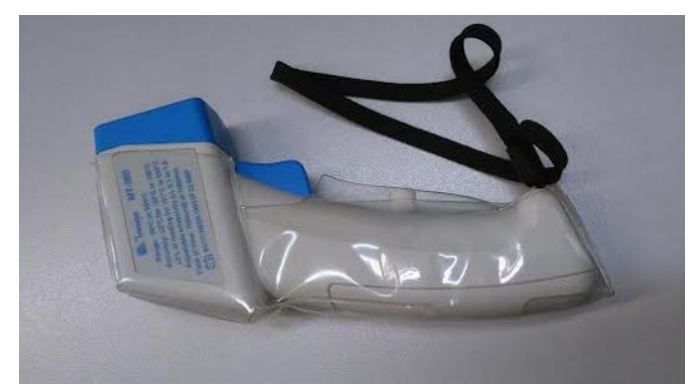

Figura 10.Termômetro digital infravermelho com mira laser (modelo MT-360)

Figure 10. Infrared digital thermometer with laser sighting (MT-360 model)

Os dados de temperatura superficial foram coletados em três períodos do dia (manhã, tarde e noite) às 08:00; 14:00 e 20:00 horas, respectivamente, conforme as recomendações da Organização Mundial de Meteorologia (OMM).

A estimativa do Índice de Área Foliar (IAF) foi realizada com o equipamento Ceptômetro, que medi a radiação solar incidente e a transmitância da radiação através do dossel. O modelo utilizado foi o Ceptômetro AccuPAR Lp-80, conforme a Figura 11. As medições serão realizadas sob as copas das espécies arbóreas em condições de céu limpo, próximo às 12 horas.

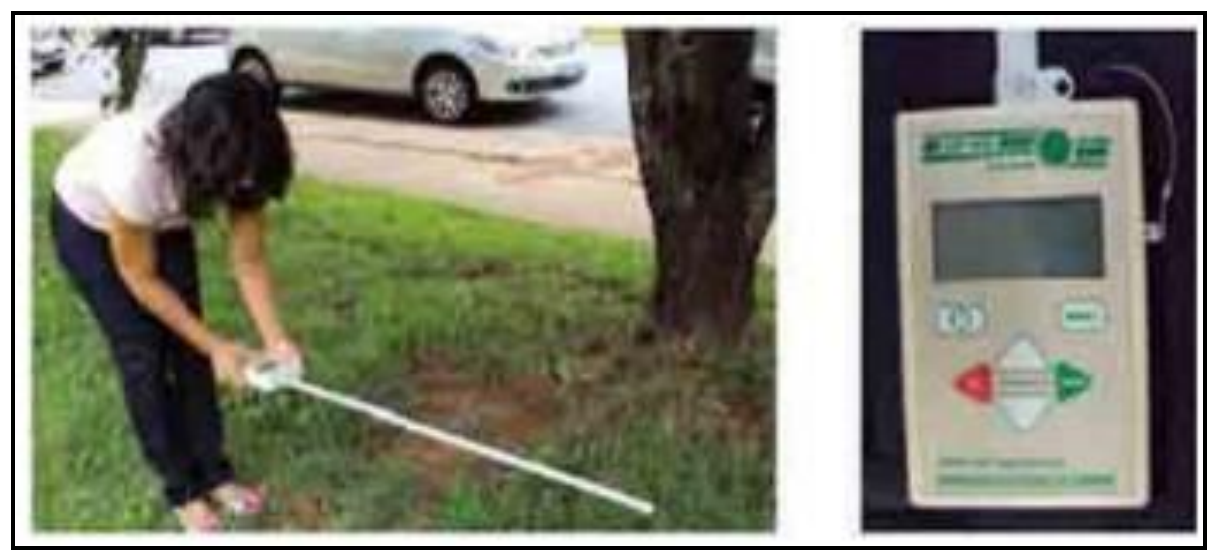

Fonte: Oliveira, 2011.

Figura 11. Equipamento Ceptômetro modelo (AccuPAR Lp-80)

Figure 11. Model Ceptômetro equipment (AccuPAR Lp-80)

Para a realização das análises estatísticas das temperaturas internas e superficiais coletadas, foram utilizados os programas SPSS 22.0 (software estatístico) e o Excel. 


\section{RESULTADOS E DISCUSSÃO}

\section{Temperaturas internas nos diferentes sombreamentos}

Na Figura 12 pode-se observar que, independente do material, a espécie Mangifera indica apresentou as menores temperaturas internas. A maior amplitude térmica nos diferentes materiais ocorreu no local sem sombreamento arbóreo, verificando-se uma diferença de $12,2{ }^{\circ} \mathrm{C}$ às 12:00 horas entre os materiais solo e asfalto, enquanto que no sombreamento proporcionado pela Mangifera indica, os materiais solo e asfalto observou-se uma diferença de $3,5^{\circ} \mathrm{C}$, no mesmo horário.

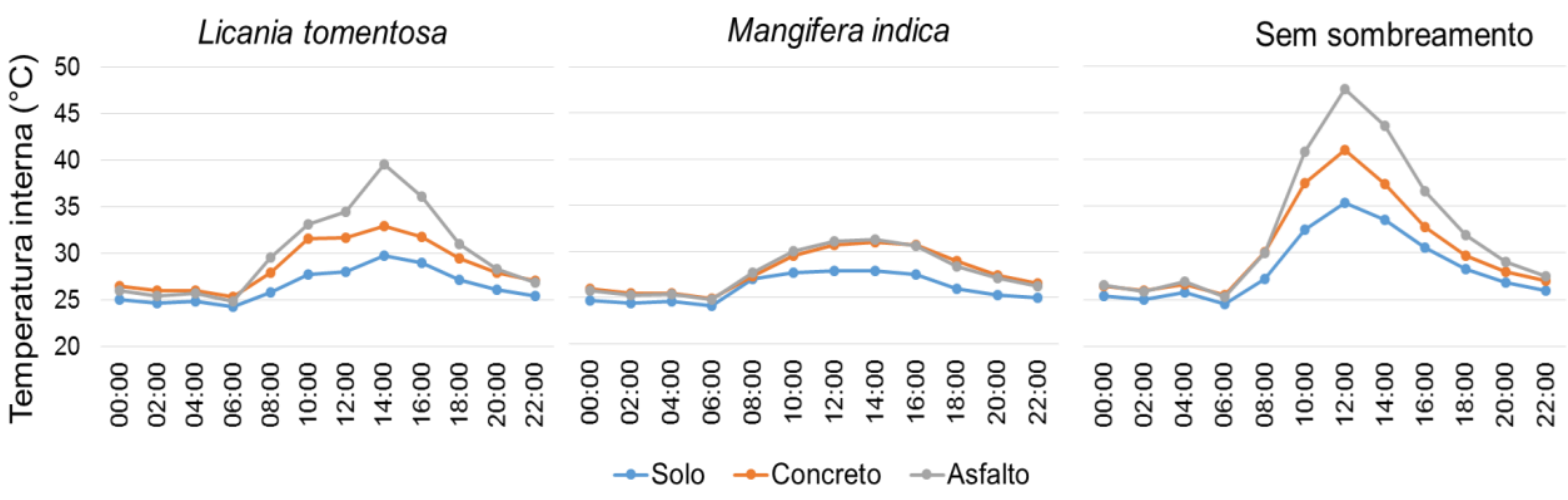

Figura 12. Médias das temperaturas internas dos diferentes locais, materiais e horários

Figure 12. Average of internal temperatures of the different sites, materials and times

Comparando as duas espécies arbóreas, a Mangifera indica apresentou melhor desempenho térmico que a espécie Licania tomentosa. Pode-se verificar que as temperaturas mais elevadas ocorreram entre às 12:00 e 14:00 horas. Isso já era esperado por causa do pico de radiação solar nesse horário. Silva, Batista e Batista (2015) observaram que a espécie Mangifera indica é a espécie favorita pela população no cenário urbano paraense com $87 \%$ de aprovação.

Abreu e Labaki (2010) concluíram que:

"Espécies perenes, como Syzygium cumini (jambolão) e Mangifera indica, têm maior influência na sensação térmica no entorno imediato. Esse fenômeno é explicado pela característica termorreguladora das árvores, que mantém a temperatura e a umidade relativa do ar a seu redor em uma faixa ideal para seu sustento. As folhas das árvores possuem células denominadas estômatos, responsáveis pela termorregulação, abrem-se quando encontram temperatura e umidade relativa do ar ideais e fecham-se 
quando começam a perder água. Sendo assim, os indivíduos arbóreos influenciam principalmente na temperatura do ar e umidade relativa do ar ao longo do ano, numa escala microclimática".

Nos estudos desenvolvidos por Durante e Nogueira (2013), pode-se observar que na espécie Mangifera indica ocorreu atenuação da temperatura do ar sob a copa durante o período de sol, chegando ao valor máximo de 16,30\% às 12 horas. Enquanto que na Licania tomentosa, a atenuação máxima foi de $10,88 \%$ e se deu às 14 horas.

Comparando-se as temperaturas internas nos dois locais (Mangifera indica e sem sombreamento arbóreo) às 12:00 horas, as diferenças nos materiais urbanos foram de 7,5 ${ }^{\circ} \mathrm{C}$ (solo), $10,3{ }^{\circ} \mathrm{C}$ (concreto) e $16,4^{\circ} \mathrm{C}$ (asfalto). O material que obteve menor diferença entre os locais foi o solo, devido o material ser permeável e facilitar a infiltração da água da chuva, deixando o solo úmido e fresco. Em contrapartida, o asfalto apresentou diferença significativa, comprovada mais à frente por uma análise de variância, mostrando o potencial para o conforto térmico que um sombreamento arbóreo proporciona.

Foi notória a elevação da temperatura dos materiais onde não existe uma barreira que filtre os raios solares, como as copas das árvores. A maior temperatura foi às $12: 00 \mathrm{com}$ $47,5^{\circ} \mathrm{C}$, no local sem sombreamento, no material asfalto (Figura 13).

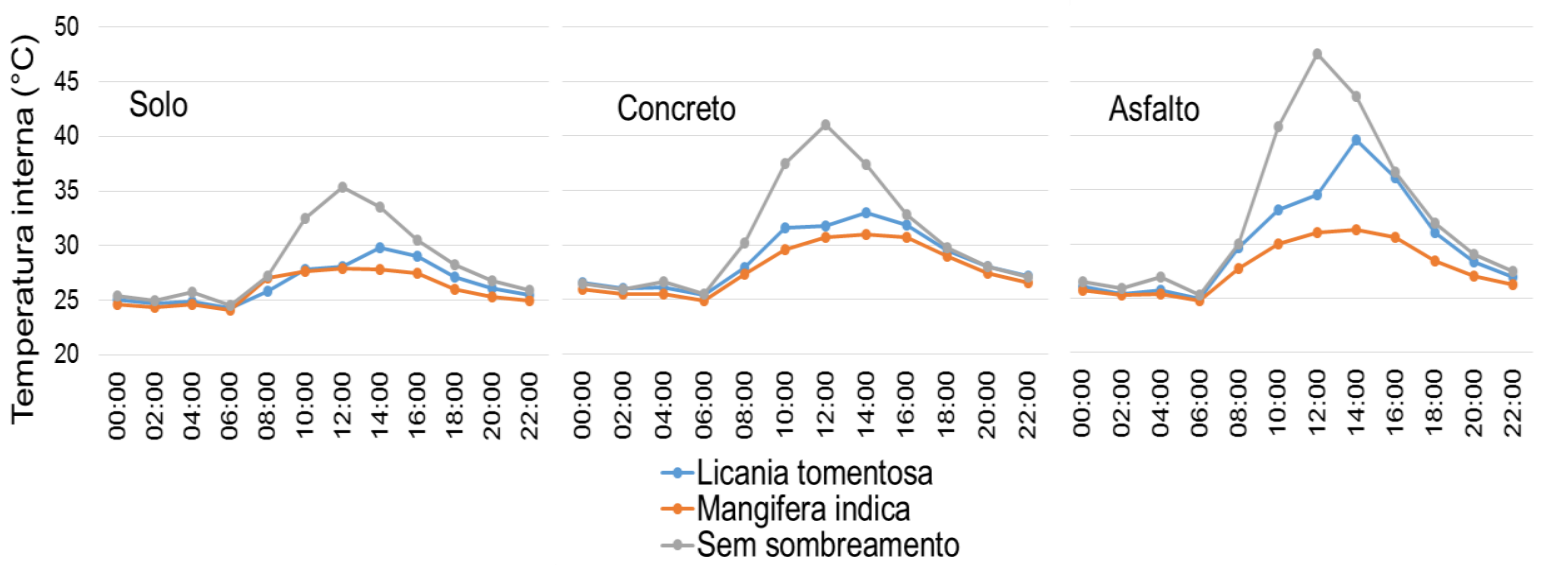

Figura 13. Médias de temperaturas internas dos diferentes materiais, locais e horários

Figure 13. Average of internal temperatures of different materials, locations and times

Mesmo em local sombreado pela espécie Licania tomentosa, o material asfalto obteve elevadas temperaturas internas, entre às 12:00 e 16:00, mostrando a importância do planejamento dos materiais utilizados nas cidades. Segundo Alves e Vecchia (2012) os materiais típicos de uma superfície urbana (asfalto e concreto) apresentam em média, menor albedo, menor capacidade térmica e maior condutividade de calor.

Rocha, Souza e Castilho (2011) verificaram a influência direta da vegetação e permeabilidade do solo na amenização do armazenamento de calor noturno. Verificou-se 
também que a maior área ocupada por construções, a maior massa construída e a maior pavimentação foram características que contribuíram para a menor perda de calor após o pôr do sol.

\section{Temperaturas superficiais nos diferentes sombreamentos}

Conforme a Figura 14, o asfalto foi o material que apresentou as maiores temperaturas superficiais nos diferentes locais (Licania tomentosa, Mangifera indica e sem sombreamento) e em todos os períodos (manhã, tarde e noite).

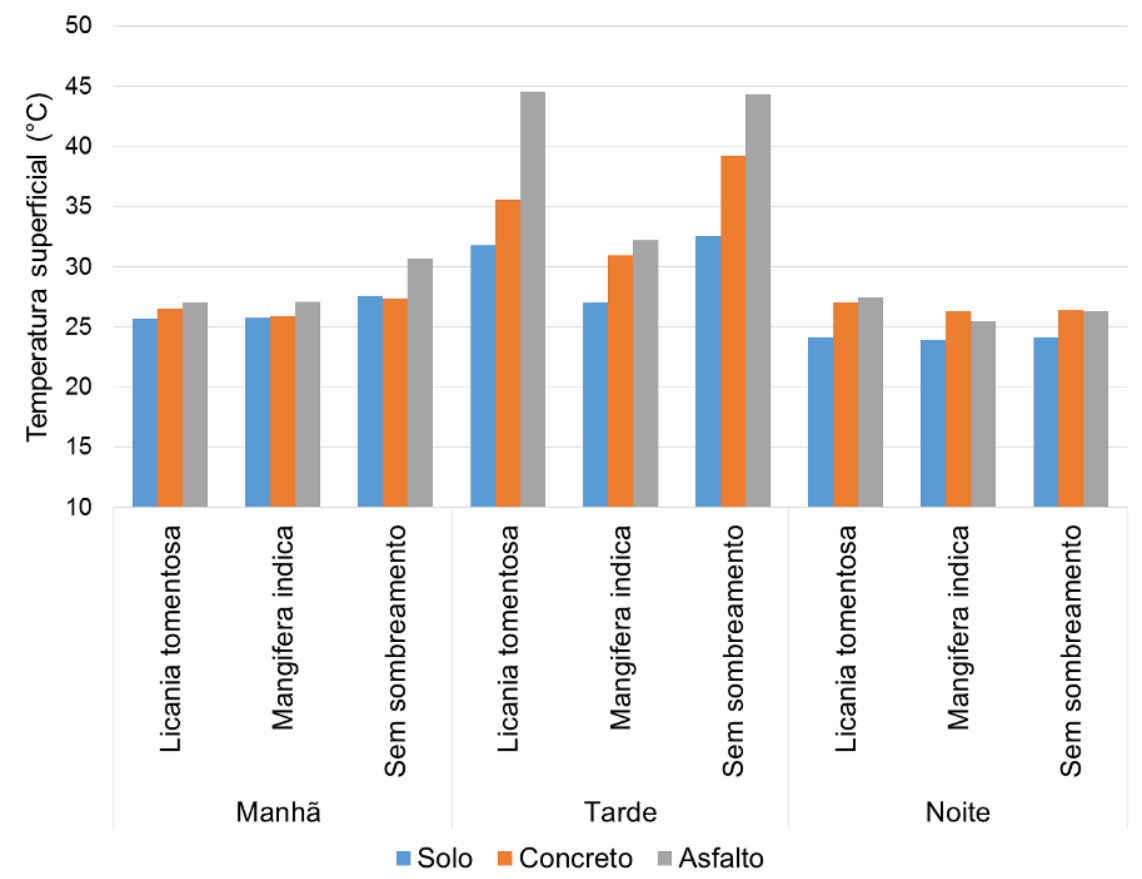

Figura 14. Média da temperatura superficial nos diferentes materiais, locais e horários Figure 14. Average of the surface temperature in different materials, locations and times

No período da manhã os locais Licania tomentosa e Mangifera indica apresentaram temperatura superficiais nos diferentes materiais entre 25 a $27{ }^{\circ} \mathrm{C}$, já no local sem sombreamento as diferenças entres os materiais urbanos variou de 27 a $31^{\circ} \mathrm{C}$. A amplitude térmica dos locais sombreados foi de $2{ }^{\circ} \mathrm{C}$ e do local sem sombra foi de $4{ }^{\circ} \mathrm{C}$.

O local que apresentou as menores temperaturas superficiais no período da manhã e da tarde, nos diferentes materiais foi sob a Mangifera indica.

Durante e Nogueira (2013) estudaram os efeitos do sombreamento arbóreo nas condições termo-higrométricas e verificaram que a Mangifera indica proporcionou maior atenuação da temperatura sob a copa que o Licania tomentosa. Sob a copa da Licania tomentosa e Mangifera indica, as temperaturas do ar foram em média 2,3 e 3,3 ${ }^{\circ} \mathrm{C}$ menores 
que a céu aberto, respectivamente. Segundo Freitas et al., (2013) a cobertura vegetal exerce papel preponderante para a manutenção das baixas temperaturas e as condições de conforto térmico.

No período da tarde, o local sem sombreamento arbóreo ficou parcialmente sombreado pela própria construção do prédio ao lado. Por esse motivo, possivelmente, os resultados de temperaturas superficiais do Licania tomentosa e sem sombreamento do material asfalto e solo foram similares.

No período da noite, os materiais tiveram comportamento térmico próximos, reportando ao quanto a radiação influência no resultado de temperaturas dos materiais, e o quanto o mal planejamento dos materiais construtivos pode intensificar a temperatura em cidades com pouca nebulosidade durante o ano inteiro, como em Cuiabá.

Barbosa e Vecchia (2009) também observaram que durante a noite há uma tendência de estabilização dos valores térmicos nos diferentes locais, verificou-se, dessa forma, que o gradiente térmico entre os espaços vegetados e os sem vegetação foi de apenas $0,8^{\circ} \mathrm{C}$.

\section{Índice de Área Foliar (IAF)}

Pode-se verificar que a espécie Mangifera indica obteve o IAF menor que da espécie Licania tomentosa, porém foi a que obteve melhor desempenho no comportamento térmico nos diferentes materiais, conforme a Tabela 3

Tabela 3. Espécies arbóreas com valores de IAF mensurados

Table 3. Arboreal species with IAF values measured

\begin{tabular}{c|c}
\hline Espécie & $\mathrm{IAF}\left(\mathrm{m}^{2} \mathrm{~m}^{-2}\right)$ \\
\hline Licania tomentosa & 4,82 \\
\hline Mangifera indica & 4,52 \\
\hline
\end{tabular}

Durante e Nogueira (2013) analisando as mesmas espécies obteve os seguintes resultados de IAF: Licania tomentosa $\left(7,4 \mathrm{~m}^{2} \mathrm{~m}^{-2}\right)$ e Mangifera indica $\left(10,1 \mathrm{~m}^{2} \mathrm{~m}^{-2}\right)$. Segundo as autoras o efeito a massa vegetada na temperatura sob a copa foi mais percebido na temperatura da Mangifera indica que na Licania tomentosa, por possuir maior índice de área foliar.

O IAF pode ser utilizado como um parâmetro facilitador na escolha de espécies que contribuam com o aumento da qualidade de ambientes urbanos, possibilitando um aumento 
na qualidade de vida e um efeito positivo na qualidade do ar e microclima, principalmente em cidades de clima quente (OLIVEIRA, 2011).

\section{Análises estatísticas}

A análise da variância (ANOVA, $\alpha<0,05)$, seguida pelo teste post hoc de Tamhane, utilizado em função de heterocedasticidades detectadas pelo teste de Levene, demostrou que em todos os locais ocorreram diferenças significativas nas temperaturas internas. Os níveis de significâncias ( $\alpha$ ) entre Mangifera indica/Licania tomentosa, Mangifera indica/sem sombreamento e Licania tomentosa/Sem sombreamento, foram respectivamente, 0,031 (diferença significativa), 0,000 (diferença altamente significativa) e 0,037 (diferença significativa). As diferentes letras "A", "B" e "C" correspondem as diferenças significativas entre os sombreamentos, conforme a Figura 15.

Pode-se observar ainda na Figura 15, que as amplitudes térmicas dos diferentes locais variaram expressivamente. Sendo que a Mangifera indica apresentou a menor amplitude e o local sem sombreamento a maior. Mostrando o impacto positivo do sombreamento da Mangifera indica, pois apresentou a menor temperatura interna e a menor variação.

Nos estudos realizados por Gonçalves, Camargo e Soares (2012) na cidade de Maringá (PR) foi observada uma redução de $1,6^{\circ} \mathrm{C}$ do ponto de coleta com arborização em relação ao sem a presença de arborização. Mostrando que o "sombreamento promovido pela arborização de acompanhamento viário, neste caso, obteve êxito na diminuição da temperatura do ar, pois o sombreamento foi capaz de promover a redução das temperaturas de superfície dos objetos sombreados".

Já nos estudos desenvolvido por Barbosa e Vecchia (2009), na cidade de Maceió $(A L)$, observou-se uma diferença térmica na ordem de $3,3{ }^{\circ} \mathrm{C}$ (no período da manhã e da tarde) entre os espaços vegetados com os ambientes sem vegetação. 


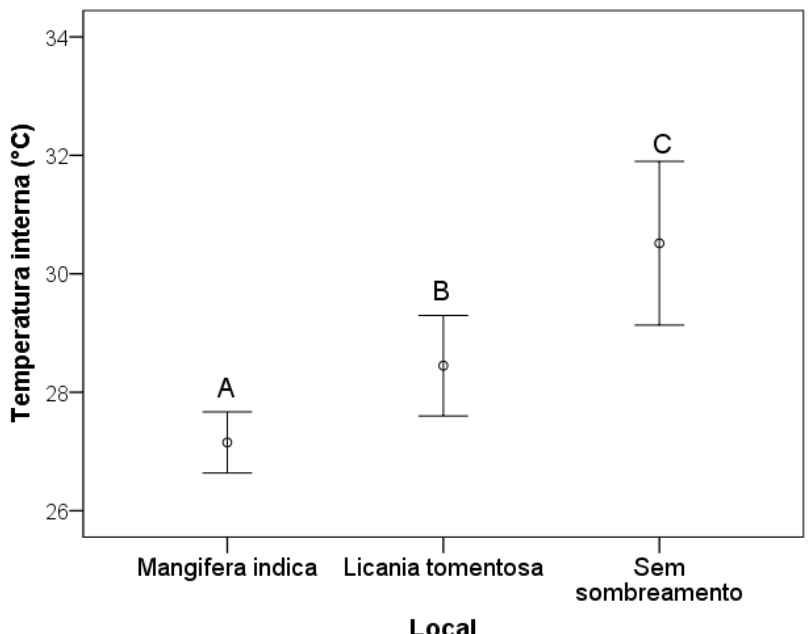

Figura 15. Gráfico de barras de amplitude de temperatura interna nos diferentes locais Figure 15. Bar graph of internal temperature amplitude in different locations

As diferenças de temperaturas internas foram altamente significativas nos materiais solo/concreto e solo/asfalto, com nível de significância igual a 0,000. O asfalto e o concreto não apresentaram diferenças significativas, $\alpha=0,414$.

O gráfico da Figura 16, apresenta essas diferenças (asfalto e concreto - Letras iguais "A") e (solo - Letra diferente "B"). Pode-se observar que o material asfalto obteve a maior temperatura interna e a maior amplitude térmica, conforme observado por Alves e Vecchia (2012), os materiais constituídos por asfalto, normalmente, apresentam maiores temperaturas se comparados aos outros materiais.

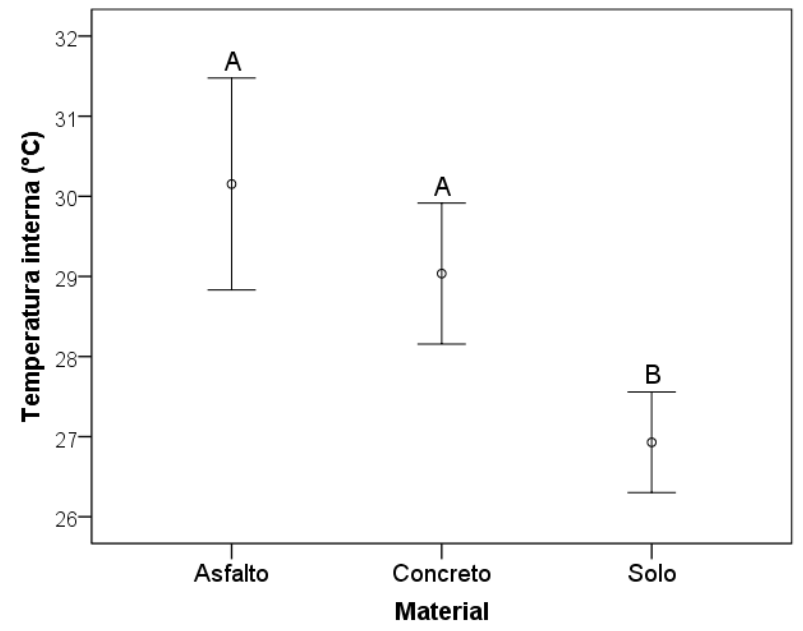

Figura 16. Gráfico de amplitude da temperatura interna nos diferentes materiais Figure 16. Amplitude graph of the internal temperature in different materials

A temperatura superficial nos diferentes locais não apresentaram diferenças significativas. Os níveis de significância foram 0,591; 0,380 e 0,986 para Mangifera indica / Licania tomentosa, Mangifera indica/sem sombreamento e Licania tomentosa/sem 
sombreamento respectivamente, ou seja, estatisticamente apresentam temperaturas superficiais equivalentes. Apesar de não terem diferenças significativa, pode-se observar que na espécie Mangifera indica a temperatura superficial obteve menor amplitude térmica (Figura 17).

Callejas et al. (2011) apontaram que os maiores valores de temperatura superficial foram registrados em locais completamente sem vegetação e em áreas que se apresentavam naturalmente desnudas.

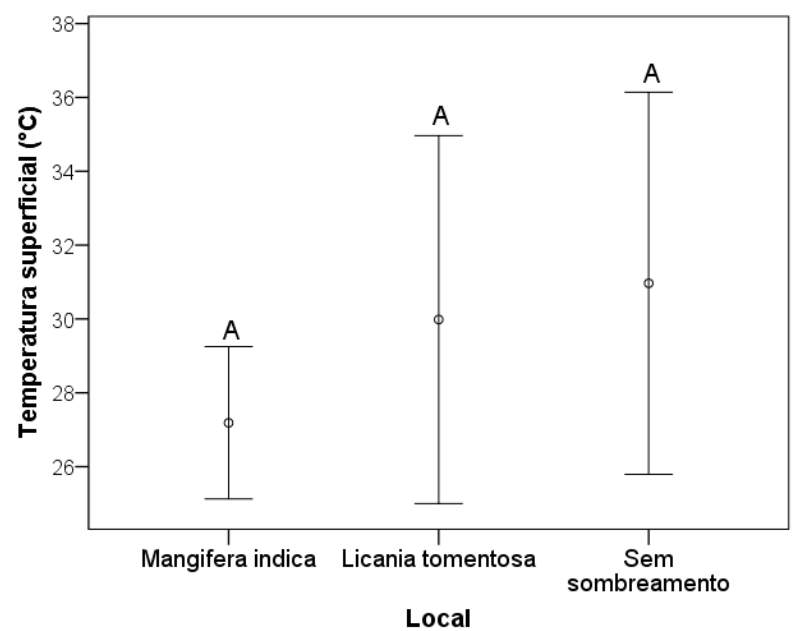

Figura 17. Gráfico de amplitude da temperatura superficial nos diferentes locais Figure 17. Amplitude graph of surface temperature in different locations

A temperatura superficial nos diferentes materiais também não apresentaram diferenças significativas, ao comparar os materiais asfalto/concreto, asfalto/solo e concreto/solo os resultados foram 0,$854 ; 0,301$ e 0,512 respectivamente, ou seja, estatisticamente apresentam temperaturas superficiais similares (Figura 18).

Oliveira (2008) realizou a caracterização microclimática da Praça do Aeroporto Marechal Rondon em Várzea Grande (MT) e observou que as médias das temperaturas superficiais coletadas nos pontos de medição estiveram entre 27,5 e $35,1^{\circ} \mathrm{C}$, abaixo do encontrado nessa pesquisa que foi de 25 a $38{ }^{\circ} \mathrm{C}$ (Figura 18). Nos estudos desenvolvidos pelo mesmo autor, "foi possível apontar uma relação quase diretas entre as maiores áreas pavimentadas e as maiores médias de temperaturas superficiais nestes locais, alteradas apenas quando a vegetação ou a sombra da edificação próxima se faziam presente". Por exemplo, local onde possuía $100 \%$ de sua área pavimentada apresentou a maior média de temperatura superficial $\left(35,0^{\circ} \mathrm{C}\right)$ e não sofreu nenhum tipo de influência de sombreamento durante o período da pesquisa. Enquanto que o local com $98 \%$ da sua área pavimentada, porém sob a influência da vegetação no seu entorno apresentou média de $31,3^{\circ} \mathrm{C}$, gerando um resfriamento passivo de $3,7^{\circ} \mathrm{C}$ devido a influência do sombreamento arbóreo. 


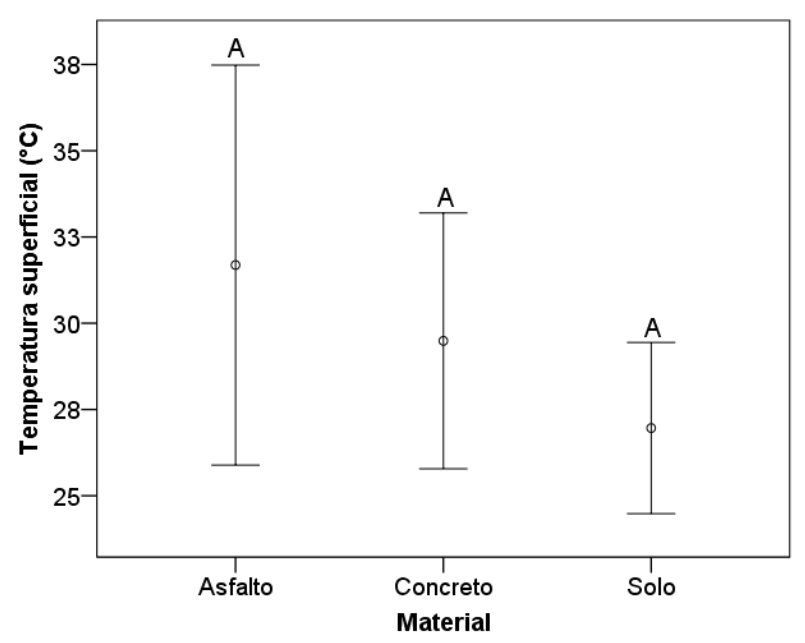

Figura 18. Gráfico de amplitude da temperatura superficial nos diferentes materiais Figure 18. Amplitude graph of surface temperature in different materials

As comparações de temperaturas superficiais nos horários das 08:00/14:00/20:00 (recomendações OMM) apresentaram os seguintes resultados: diferenças significativas $\alpha=0,010-08: 00 / 14: 00)$, diferenças altamente significativas ( $\alpha=0,004-14: 00 / 20: 00)$ e não significativos ( $\alpha=0,165$ - 08:00/20:00). No período da tarde devido a maior incidência da radiação, apresentou diferenças significativas entre os demais horários, conforme a Figura 19.

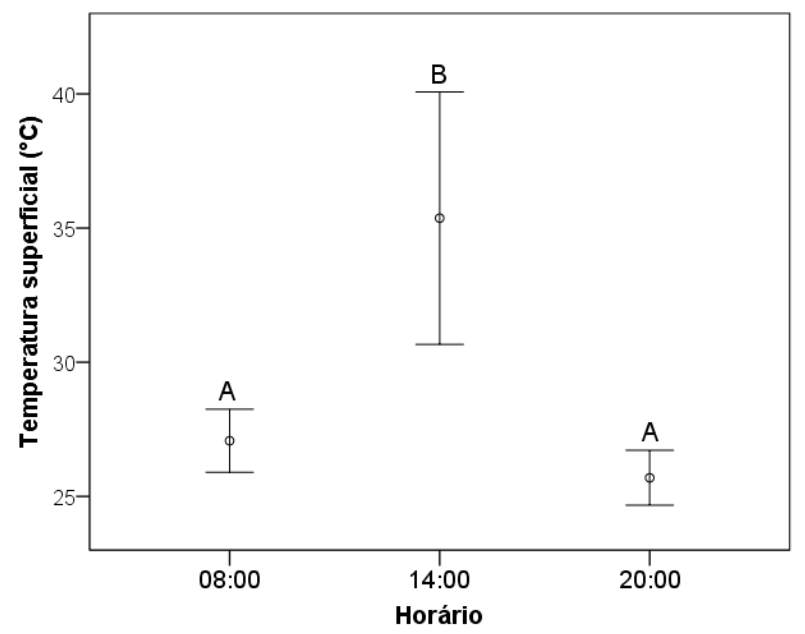

Figura 19. Gráfico de amplitude da temperatura superficial nos diferentes horários Figure 19. Amplitude graph of surface temperature at different times 


\section{CONCLUSÃO}

A espécie arbórea que obteve o melhor desempenho térmico nos diferentes materiais e menor amplitude térmica foi a Mangifera indica. O solo foi o material que resultou nas menores médias de temperaturas internas e superficiais, por ser um material permeável.

Não foram observadas diferenças estatisticamente significativas para as temperaturas superficiais nos diferentes sombreamentos e nos diferentes materiais urbanos (solo, concreto e asfalto).

Porém nas temperaturas internas foram detectados diferenças significativas entre as médias dos diferentes sombreamentos e entre os materiais solo/asfalto e solo/concreto. A maior diferença térmica interna dos diferentes sombreamentos ocorreu entre a Mangifera indica e o local sem sombreamento, com $16,4^{\circ} \mathrm{C}$ a menos para o material asfalto instalado sob a copa da Mangifera indica. Esse comportamento foi decorrente do bloqueio da radiação através da copa da Mangifera indica, que diminuiu as temperaturas internas da área sombreada.

Os resultados mostraram melhores desempenhos térmicos nas áreas com sombreamento arbóreo. Cabe ressaltar a importância da arborização nas cidades para proporcionar melhor conforto térmico aos usuários. Ao utilizar-se da arborização urbana, as contribuições e benefícios são estratégias de resfriamento evaporativo, umidificação, melhoramento do microclima, que resultará em um ambiente externo mais atrativo e adequado ao uso.

\section{AGRADECIMENTOS}

Os autores agradecem o apoio e incentivo financeiro da FAPEMAT.

\section{REFERÊNCIAS}

ABREU, L. V.; LABAKI, L. C. Conforto Térmico Propiciado por Algumas Espécies Arbóreas: avaliação do raio de influência através de diferentes índices de conforto. Ambiente Construído, Porto Alegre, v. 10, n. 4, p. 103 - 117, 2010.

ALMEIDA JÚNIOR, N. L. de. Estudo de clima urbano: uma proposta metodológica. 109 f. Dissertação (Mestrado em Física e Meio Ambiente) - Universidade Federal de Mato Grosso, Cuiabá, 2005. 
ALVES, E. D. L.; BIUDES, M. S. Padrões da temperatura do ar e da umidade relativa: estudo de caso no campus de Cuiabá da Universidade Federal de Mato Grosso. Boletim de Geografia, Maringá, v. 30, n. 3, p. 5 - 16, 2012.

ALVES, E. D. L.; VECCHIA, F. A. S. Influência de diferentes superfícies na temperatura e no fluxo de energia: um ensaio experimental. Ambiência, Guarapuava, v. 8, n. 1, p. 101 - 111, 2012.

BARBOSA, R. V. R. F.; VECCHIA, F. A. S. Análise do comportamento térmico de diferentes arranjos urbanos na cidade de Maceió (AL) em escala de abordagem microclimática. Revista PARC, Campinas, v. 1, n. 4, 2009.

BRASQUÍMICA. Produtos asfálticos. Disponível em: <http://www.brasquimica.com.br/produtos/prg_pro.cfm?cod=13> Acesso em 10 jun 2015.

CALLEJAS, I. J. A.; DURANTE, L. C.; OLIVEIRA, A. S. de; NOGUEIRA, M. C. D. J. A. Uso do solo e temperatura superficial em área urbana, Universidade Federal do Ceará, Brasil. Revista Mercator, Fortaleza, v. 10, n. 23, p. 207 - 223, 2011.

DURANTE, L.; NOGUEIRA, M. C. de J. A. Efeitos do sombreamento arbóreo nas condições termo-higrométricas e lumínicas de ambientes internos e externos de edificações. Revista Eletrônica em Gestão, Educação e Tecnologia Ambiental, Santa Maria, v. 9, n. 9, p. 1980 - 1998, 2013.

FREITAS, A. F. de; MELO, B. C. B. de; CEVADA, C. M.; SANTOS, J. S. dos e ARAÚJO, L. E. de. Avaliação Microclimática em Dois Fragmentos Urbanos Situados no Campus I e IV da Universidade Federal da Paraíba. Revista Brasileira de Geografia Física, Recife, v. 6, n. 4, p. 777 - 792, 2013.

GONÇALVES, A.; CAMARGO, L. S.; SOARES, P. F. Influência da vegetação no conforto térmico urbano: Estudo de caso na cidade de Maringá - Paraná. Anais do III Seminário de Pós-Graduação em Engenharia Urbana, 2012.

GOOGLE. Google Earth website. Disponível em <http://earth.google.com/>. Acesso 14 out 2015.

LIMA NETO, E. M., MELO E SOUZA, R. Comportamento e características das espécies arbóreas nas áreas verdes públicas de Aracaju, Sergipe. Scientia Plena, Sergipe, v. 7, n. 1, p. $01-10,2011$.

MACIEL, C. de R.; NOGUEIRA, M. C. de J. A.; NOGUEIRA, J. de S. Cobertura do solo e sua influência na temperatura de microclimas urbanos na cidade de Cuiabá - MT. Caminhos de Geografia, Uberlândia, v. 12, n. 39, p. 40 - 57, 2011.

NINCE, P. C. do C.; SANTOS, F. M. de M.; NOGUEIRA, J. de S.; NOGUEIRA, M. C. D. J. A. Conforto térmico dos usuários em vegetação e revestimentos urbanos no campus da UFMT em Cuiabá-MT. Revista Monografias Ambientais, Santa Maria, v. 13, n. 4, p.3299 - 3305, 2014.

OLIVEIRA, A. G. Avaliação das Temperaturas Superficiais do Solo em relação à Conformação Urbana existentes na Praça do Aeroporto Marechal Rondon em Várzea Grande / MT. 74 f. Dissertação (Mestrado em Física e Meio Ambiente) - Universidade Federal de Mato Grosso, Cuiabá, 2008. 
OLIVEIRA, A. S. de. Influência da vegetação arbórea no microclima e uso e praças públicas. $162 \mathrm{f}$. Tese (Doutorado em Física Ambiental) - Universidade Federal de Mato Grosso, Cuiabá, 2011.

OLIVERA, S. M.de S. Avaliação do impacto do uso do fruto Mangifera indica L. (manga) no tratamento de crianças anêmicas fazendo uso do sulfato ferroso. $127 \mathrm{f}$. Tese (Doutorado em Produtos Naturais e Sintéticos Bioativos) - Universidade Federal da Paraíba. Brasil, 2009.

RIBEIRO JÚNIOR, I. Estabilização da Expansão do Solo Saprolítico de Filito com Cal Hidratada Cálcica. 77 f. Trabalho de conclusão de curso (Graduado em Engenharia Civil) Universidade Federal de Mato Grosso, Cuiabá, 2006.

ROCHA L. M. V.; SOUZA L. C. L.; CASTILHO F. J. V. Ocupação do solo e ilha de calor noturna em avenidas marginais a um córrego urbano. Ambiente Construído, Porto Alegre, v. 11, n. 3, p. 161-175, 2011.

SANTOS, F. M. de M.; MUSIS, C. R., NOGUEIRA, de S. J.; JÚNIOR, O. B. P.; NOGUEIRA, M. C. D. J. A. Análise da variação higrotérmica ocasionada pela influência da ocupação do solo na cidade de Cuiabá - MT. Revista Eletrônica em Gestão, Educação e Tecnologia Ambiental, Santa Maria, v. 9, n. 9, p. 1932 - 1945, 2013.

SILVA, D. A.; BATISTA, D. B.; BATISTA, A. C. Percepção da população quanto a arborização com Mangifera indica l. (mangueira) nas ruas de Belém-PA. Revista da Sociedade Brasileira de Arborização Urbana, Piracicaba, v. 10, n. 1, p. 1 - 18, 2015. 